\title{
A LINGUAGEM NÃO VERBAL E A CONTAÇÃO DE HISTÓRIAS NA PERSPECTIVA DO PROJETO PALAVRAS ANDANTES
}

\author{
EL LANGUAJE NO VERBAL Y LA NARRACIÓN EM LA \\ PERSPECTIVA DEL PROYECTO "PALAVRAS ANDANTES"
}

\begin{abstract}
Rosane A. S. Lunardelli - lunardelli@uel.br Doutora em Linguística pela Universidade Estadual de Londrina (UEL). Professora do Programa de Pós-Graduação em Ciência da Informação da
\end{abstract} (UEL).

Juliana Cristina Gonçalves Meirelles - jcgmeirelles@gmail.com

Especialista em Gestão de Biblioteca Escolar pela Universidade

Estadual de Londrina (UEL).

\begin{abstract}
RESUMO
Introdução: O presente artigo traz alguns dos resultados apresentados em uma monografia do Curso de Especialização em Gestão de Bibliotecas Escolares da Universidade Estadual de Londrina.

Objetivo: Investigar qual é a percepção dos profissionais que realizam a Hora do Conto nas escolas do Município de Londrina, a respeito da importância da linguagem não verbal para a realização dessa atividade.

Metodologia: A metodologia empregada foi de abordagem qualitativa, efetivada por meio de pesquisa exploratória e descritiva na qual foi aplicada um questionário aos sujeitos mencionados.

Resultados: Observou-se, entre outros aspectos, que a maioria dos contadores se vale, de forma intuitiva, de alguns dos aspectos da linguagem não verbal em suas ações. A importância acerca da proximidade e das configurações espaciais na Hora do Conto, entretanto, ainda não são suficientemente valorizadas pelos profissionais.

Conclusões: Por meio da pesquisa realizada, entende-se que, ao adquirirem conhecimento mais aprofundado de tal assunto, a qualidade da hora do conto melhorará significativamente. Nesse sentido, espera-se, com o estudo em pauta, contribuir para a reflexão dos contadores de histórias quanto à importância da linguagem não verbal na contação de histórias.
\end{abstract}


Palavras-chave: Hora do conto. Biblioteca escolar. Linguagem não verbal. Paralinguagem. Cinésica. Proxêmia.

\section{INTRODUÇÃO}

Ler, é fato, constitui-se em ato de extrema valia para o desenvolvimento cultural e social de qualquer cidadão. A literatura especializada aponta que o incentivo à leitura deveria iniciar no ambiente familiar. Nessa linha de raciocínio Silva e Bortolin (2006) ao ratificarem a ideia que os familiares deveriam ser os primeiros a apresentarem as crianças ao mundo da leitura, ressaltam que os pais geralmente desconhecem a influência que podem exercer sobre as crianças, incentivando-as a lerem desde a mais tenra idade. Entretanto, muitas crianças têm seu primeiro encontro com o livro e com a literatura infantil na biblioteca da escola. Nesse sentido, pode-se afirmar que a biblioteca escolar exerce papel fundamental na educação, pois é nela que as crianças têm a oportunidade de dar seus primeiros passos rumo ao mundo da leitura.

De acordo com o panorama apresentado, torna-se evidente que a biblioteca escolar é um espaço propício ao crescimento intelectual e emocional da criança, pois segundo Caldeira (2005, p. 48), ela

[...] oferece excelentes oportunidades para o exercício da cidadania e para a prática de zelo pelo patrimônio comum, representado pelos materiais da coleção e equipamentos. Dessa forma, a biblioteca amplia sua influência pedagógica, participando definitivamente da formação de uma pessoa integral, eliminando seu estigma de espaço para castigo de alunos ou de depósito de materiais.

Além dos benefícios à aprendizagem, a inserção ao mundo mágico da leitura proporciona momentos de lazer, entretenimento e acesso às experiências e situações vividas pelos personagens.

De acordo com essa premissa, vale ressaltar que um dos meios de propiciar ao aluno a oportunidade de desenvolver o gosto e o hábito de leitura é apresentar-lhes textos literários por meio da linguagem verbal e da não verbal, isto é, das palavras, dos gestos 
corporais e expressões faciais. Diante disso, evidencia-se a atividade desenvolvida na biblioteca escolar denominada Contação de Histórias ou Hora do Conto ${ }^{1}$.

Abramovich (1997, p. 16) destaca o quão importante é para a "[...] formação de qualquer criança ouvir muitas, muitas histórias... Escutá-las é o início de aprendizagem para ser um leitor, e ser leitor é ter um caminho absolutamente infinito de descoberta e de compreensão do mundo...". Dando continuidade ao raciocínio, a autora (1997, p. 17), afirma que a atividade de contar histórias possibilita às crianças a oportunidade de "[...] ouvir, sentir e enxergar com os olhos imaginários."

Para Borges e Bortolin (2006, p. 142) contar histórias é uma arte e sua essência está na "[...] preocupação de trabalhar o imaginário, a afetividade e a emoção do ouvinte."

Ao reportar-se aos aspectos de relevância na realização da Hora do Conto, Coelho (1998, p. 50) salienta que "[...] as emoções se transmitem pela voz, principal instrumento do narrador [...]", porém sua postura também influencia a qualidade da apresentação da história. Na Contação de Histórias, segundo a autora (1998, p. 50) são "[...] indispensáveis sobriedade nos gestos e equilíbrio na expressão corporal."

Contar histórias não é simplesmente escolher um livro e se posicionar diante de uma plateia; a qualidade dessa atividade não está relacionada somente ao uso de palavras e termos adequados à maturidade do ouvinte bem como ao seu cotidiano, mas depende também da distância física mantida entre o contador e seus ouvintes, dos gestos, entonações e expressões corporais empregadas na atividade.

Diante do afirmado, observa-se que a linguagem não verbal, ou seja, - a expressão corporal, as mensagens que são enviadas por meio de gestos e posturas corpóreas, a distância física, bem como as variações vocais, as entonações -, são considerados fatores de suma importância na comunicação entre o contador e seus ouvintes.

De acordo com esse contexto de valorização da comunicação não verbal na contação de histórias, surge então a questão norteadora do estudo, isto é, qual é a percepção dos contadores de histórias que realizam a Hora do Conto nas bibliotecas escolares da Prefeitura Municipal de Londrina a respeito da importância da linguagem não verbal para a realização de suas atividades?

Considerando que a Hora do Conto é uma atividade que se institui por intermédio da comunicação verbal e não verbal, o intuito dessa pesquisa foi de ressaltar a

\footnotetext{
${ }^{1}$ Para o desenvolvimento deste trabalho foram empregadas as expressões "Contação de Histórias" para caracterizar o ato de contar histórias e "Hora do Conto" para identificar a atividade em si.
} 
importância da linguagem não verbal, - e sua adequada utilização -, nesse evento comunicativo e com isso suscitar, por parte dos contadores de histórias, reflexões a respeito do tema.

Ainda que tenha sido insuficientemente abordadas questões a respeito da linguagem verbal na Contação de Histórias, é possível encontrar na literatura especializada, alguns estudos acerca dos gestos e da entonação de voz. Entretanto, no que diz respeito à distância entre o contador e seus ouvintes, é inegável a escassez de pesquisas e análises acuradas. Em outros termos é possível afirmar que poucos são os estudos que privilegiam a linguagem não verbal na Hora do Conto. Dada a importância dessa atividade para a valorização e o gosto pela leitura, espera-se, por meio do presente estudo, subsidiar os contadores de histórias de bibliotecas escolares e outros contextos.

\section{BIBLIOTECA ESCOLAR}

A biblioteca merece papel de destaque dentro de toda e qualquer instituição de ensino, visto que os materiais ali armazenados e organizados podem mudar a vida de qualquer cidadão. $O$ acesso à biblioteca permite ir além do conteúdo apresentado em sala de aula, pois ela oferece uma diversidade de documentos e atividades capazes de contribuir para a construção de um indivíduo mais crítico e criativo.

A biblioteca escolar (BE) exerce papel fundamental na formação integral do aluno. Segundo Silva (2003, p. 67) é na biblioteca escolar "[...] que a maior parte das nossas crianças terão a oportunidade, muitas vezes única em suas vidas, de contato com livros e outros documentos." Nesse sentido, é possível afirmar que a biblioteca escolar desempenha papel de extrema importância no contexto escolar, pois além de dar suporte aos trabalhos dados em classe, proporciona o convívio com a leitura, contribuindo com a formação do leitor crítico, criativo e independente.

De acordo com Castro Filho e Coppola Júnior (2012), a biblioteca escolar é uma importante aliada para garantir melhor qualidade de ensino, bem como ampliar o acesso aos livros e à leitura na educação pública.

De acordo com os Parâmetros Curriculares Nacionais (PCNs) os quais "[...] constituem um referencial de qualidade para a educação no Ensino Fundamental em todo o País." (BRASIL, 1997b, p. 9), a escola tem o papel de ensinar o aluno a ler, escrever, 
bem como produzir e interpretar textos. Tais Parâmetros destacam que no momento em que as crianças são iniciadas no mundo da escrita, elas precisam ter contato com textos de qualidade.

Nessa perspectiva, os PCNs (BRASIL, 1997a) reconhecem que a biblioteca escolar é fundamental para o desenvolvimento de um programa de leitura eficiente, que forme leitores competentes e não leitores que leiam esporadicamente, uma vez que, "[...] a biblioteca é um espaço apto a influenciar o gosto pela leitura." (CAMPELLO, 2005, p. 17). $\mathrm{Na}$ concepção dos Parâmetros, na biblioteca da escola os alunos devem encontrar textos de gêneros variados, dentre eles: os livros de contos, romances, poesia, enciclopédias, dicionários, jornais, revistas (infantis, em quadrinhos, de palavras cruzadas e outros jogos), entre outros.

No que diz respeito à atuação das bibliotecas escolares, Bamberger (1995) menciona que nos países desenvolvidos as bibliotecas dedicam-se a organizar diversas atividades e acontecimentos que permitam que a criança entre em contato com os livros, dentre as atividades, destacam-se: horas de histórias, relatórios sobre livros, grupos de discussão, leitura feita por autores etc.

Na perspectiva de Ferraz (2009, p. 2):

A BE tem papel relevante na vida dos alunos (as) desde a idade préescolar, onde deveria ser presença obrigatória na infância dos indivíduos através das atividades como 'A hora do conto', conduzindo-lhes ao mundo da leitura por meio de textos diversos, que propiciam espírito crítico, desenvolvimento intelectual e social.

A biblioteca, além de selecionar, organizar, realizar empréstimos e auxiliar no uso das fontes de informação, realiza outras ações que contribuem para o processo de ensino-aprendizagem e também com a formação de leitores. Dentre as atividades que podem ser desenvolvidas pela biblioteca escolar para promoção e incentivo da leitura, destaca-se a Hora do Conto.

\section{HORA DO CONTO E CONTAÇÃO DE HISTÓRIAS}

O ato de contar histórias é considerado uma arte milenar e toda criança, ou até mesmo adolescentes e adultos, necessitam ouvir histórias, pois por meio delas o gosto pela leitura certamente poderá ser despertado. 
A Hora do Conto, de modo geral, é definida como reunião de atividades realizadas em um espaço físico predeterminado, durante um período específico, no qual são apresentadas histórias e, muitas vezes, após a contação de histórias são desenvolvidas atividades de pinturas, recortes, colagens, entre outras.

Do ponto de vista de Barcellos e Neves (1995, p. 19) "[...] a Hora do Conto amplia os horizontes de leitura [...]", pois de acordo com os autores, tal atividade tem a capacidade de aproximar a criança de uma infinidade de livros de diversos temas, gêneros e estilos, os quais podem satisfazer suas necessidades individuais e seus gostos, permitindo a seleção de obras que se ajustem ao seu grau de maturidade psíquica e intelectual.

Abramovich (1997, p. 24), ao reportar-se à atividade mencionada argumenta que "[...] ouvir histórias é viver um momento de gostosura, de prazer, de divertimento dos melhores. É encantamento, maravilhamento, sedução... O livro da criança que ainda não lê é a história contada." A Contação de Histórias, possibilita, entre outras situações, a formação de leitores.

A literatura infantil é um dos recursos utilizados pelos contadores de histórias e pode ser considerada a porta de entrada para os sonhos, imaginação, criatividade, sensibilidade, pensamentos, sentimento e emoções. A criança precisa ser apresentada a todas essas possibilidades. Nessa perspectiva, Coelho (2000, p. 27) afirma que:

A literatura infantil é, antes de tudo, literatura: ou melhor, é arte: fenômeno de criatividade que representa o mundo, o homem, a vida, através da palavra. Funde os sonhos e a vida prática, o imaginário e o real, os ideais e sua possível/impossível realização...

Um dos meios de se introduzir a criança no mundo das leituras quer seja ela alfabetizada ou não, é propiciar-Ihe momentos em que ela possa ouvir as mais diversas histórias e também que lhe permita falar a respeito do que ouviu, além de escutar os colegas. Esses momentos são comumente denominados Hora do Conto.

$\mathrm{Na}$ Contação de Histórias diversas maneiras e diferentes recursos podem ser utilizados. Coelho $(1998$, p. 31) destaca que "[...] os recursos mais utilizados são: a simples narrativa, a narrativa com o auxílio do livro, o uso de gravuras, de flanelógrafo, de desenhos e a narrativa com interferências do narrador e do ouvinte."

A autora destaca que a forma mais fascinante de se contar histórias é a simples narrativa, pois não requer nenhum acessório, é uma atividade que o narrador faz uso de 
sua voz e sua postura, por sua vez "[...] com as mãos livres, concentra toda sua força na expressão corporal." (COELHO, 1998, p. 31). De acordo com Barcellos e Neves (1995) esta modalidade é muito utilizada para narração de contos de fadas, pois leva a criança a desenvolver a criatividade, isto é, a criança pode imaginar a bruxa, o castelo da princesa, o príncipe encantado, entre outros.

A literatura especializada sinaliza uma diversidade de modos de se contar histórias, vestuários e adereços adequados, entre outros fatores. Em decorrência, verifica-se que não há uma regra geral, tudo vai de acordo com o texto, contexto, características e particularidades do contador.

\section{1 Contadores de Histórias}

Os contadores de histórias são conhecidos desde os primórdios da humanidade. De acordo com Caldin (2002, p. 5) "[...] nas sociedades primitivas, os contadores de histórias eram muito respeitados, pois se reputavam como a memória da comunidade." Os antigos contadores geralmente se reuniam ao redor do fogo para narrar histórias, mitos, costumes, lendas, fatos históricos, causos, propagando-os de geração em geração.

Para Busatto (2006) os contadores de histórias são caracterizados como contador tradicional e contador contemporâneo. Segundo a autora, o contador tradicional é aquele sujeito que se revelava no seio da sua comunidade, e o contador contemporâneo é este sujeito da atualidade, o qual elegeu a expressão contador de histórias para definir uma profissão, um ofício. Com o passar do tempo muda-se a forma de contar, entretanto, permanece o que é considerado essencial: a condição de encantar.

É possível afirmar que para contar histórias não existe uma uniformidade, pois cada contador conta, diferente do outro, a mesma história (SISTO, 2012). Entretanto, tal atividade requer certas habilidades, como por exemplo, conhecimento acerca da história, gosto pela atividade, capacidade de estabelecer empatia entre ele e seus ouvintes, entre outros aspectos.

Diante do contexto, observa-se que na arte de contar histórias outra questão reveste-se de importância uma vez que é fundamental a realização da atividade. Esse aspecto diz respeito à preocupação com a linguagem não verbal presente em toda $\mathrm{e}$ qualquer Contação de Histórias. Piza (2006, p. 19) destaca na atividade a influência do “[...] narrar na expressão do corpo, na tonalidade da voz e no olhar do contador para com 
os seus ouvintes." Sisto (2012, p. 101) afirma que "[...] o contador de histórias é um todo orgânico que se expressa pela voz, pelo corpo e pelas expressões faciais [...]".

De acordo com Busatto (2003, p. 9) "[...] o contador de histórias empresta seu corpo, sua voz e seus afetos ao texto que ele narra, e o texto deixa de ser signo para se tornar significado."

Nesse panorama, destaca-se a importância dos contadores de histórias terem o conhecimento de que a comunicação não verbal interfere fortemente e positivamente na realização da atividade de contar histórias.

\section{LINGUAGEM NÃO VERBAL: CINÉSIA, PROXÊMIA E PARALINGUAGEM}

A comunicação é um processo de interação social entre seres humanos e componente vital à sobrevivência dos indivíduos. Os homens emitem e recebem mensagens por intermédio da linguagem verbal e/ou não verbal. Em que pese a importância dessas duas modalidades linguísticas, a esse estudo interessa a linguagem não verbal. Adler e Towne (2002, p. 110) definem essa forma de "[...] comunicação nãoverbal como as 'mensagens expressas por outros meios que não os lingüísticos'."

Para Santaella (2002, p. 22) "A comunicação é inevitável porque, mesmo quando não queremos, estamos o tempo todo emitindo mensagens para o outro [...]". Tal afirmação pode ser comprovada ao perceber as expressões faciais e gestuais de um indivíduo que se nega a participar de uma conversa. Ele não precisa utilizar a palavra falada para dizer não, a linguagem não verbal demonstrará a sua intenção.

No que diz respeito à comunicação não verbal, Silva et al. (2000, p. 53) ressaltam que ela

[...] exerce fascínio sobre a humanidade desde seus primórdios, pois envolve todas as manifestações de comportamento não expressas por palavras, como os gestos, expressões faciais, orientações do corpo, as posturas, a relação de distância entre os indivíduos e, ainda, a organização dos objetos no espaço.

Rector e Trinta (1999, p. 8) afirmam que "[...] comunicar é manifestar uma presença na esfera da vida social." Os autores destacam que o comportamento não verbal, além de se ajustar à expressão linguística, permite e favorece a expressão de intenções e de estados afetivos. A comunicação não verbal nos permite definir que tipo de 
relacionamento que queremos ter com outras pessoas. Ao cumprimentar alguém, a pessoa pode sorrir, acenar, trocar um aperto de mão, abraçar, bem como evitar todo e qualquer contato (ADLER; TOWNE, 2002).

Lemos (2006, p. 3) destaca que "A comunicação não verbal é uma fonte muito rica em mensagens que incide sobre a comunicação verbal [...]", visto que, os sinais não verbais podem confirmar, complementar e até contradizer a mensagem verbalizada.

Para Guiraud (2001, p. 5) "[...] falamos com o nosso corpo e o nosso corpo fala. De diversas maneiras e em diversos níveis." A comunicação não verbal se expressa pela movimentação significativa do corpo. Por meio de gestos, expressão facial, entonação de voz, postura, o homem pode transmitir mensagens, ideias e emoções.

Conforme natureza e função, os códigos corporais de acordo com Guiraud (2001, p. 6) podem apresentar diferentes tipos, sendo eles: "[...] os substitutos da linguagem articulada, nos quais o gesto e a mímica suprem os sons (linguagem dos surdos-mudos [...]" e os "[...] auxiliares a linguagem articulada, nos quais os gestos ou outros movimentos do corpo acompanham a fala [...]".

A partir do estudo dos auxiliares da linguagem articulada, deu-se início a origem a três novas disciplinas, a cinésica, proxêmica e prosódica, conforme explicita Guiraud (2001, p. 6):

- a cinésica ou estudo dos gestos e mímicas;

- a proxêmica ${ }^{2}$ ou estudo das posições do corpo no espaço cultural; assim - abraço, a posição num cortejo, a distância mantida entre os interlocutores etc.;

- a prosódica ${ }^{3}$ ou estudo das entonações e variações da voz por meio das quais se exprimem os sentimentos e intenções dos interlocutores. À qual competem, também os gritos, as lágrimas, os risos, os suspiros, sobre os quais pouco ou nada se conhece.

Assim sendo, pode-se afirmar que os estudos a respeito da linguagem não verbal são divididos em cinésia, proxêmia e paralinguagem. Vale ressaltar que ter conhecimento da influência da linguagem não verbal em ações profissionais e cotidianas pode contribuir para a qualidade das atividades desenvolvidas pelos indivíduos.

\footnotetext{
${ }^{2}$ Apesar de serem grafados de forma diferente, os termos proxêmica e proxêmia serão empregados no estudo como equivalentes.

${ }^{3} \mathrm{O}$ mesmo se aplica a prosódica e paralinguagem.
} 


\subsection{Cinésia}

A cinésia ou cinésica é a área do conhecimento que se preocupa com as mensagens que são enviadas por meio de expressões faciais, gestos e posturas corpóreas, uma vez que "[...] a linguagem do corpo diz muitas coisas tanto para nós quanto para aqueles que nos rodeiam." (SILVA et al., 2000, p. 53).

Segundo Rector e Trinta (1999, p. 51) "O termo cientifico cinésica (inglês Kinesics, do grego Kinesis, (movimento') designa uma disciplina aplicada ao estudo do comportamento comunicativo do corpo humano." De um modo simplificado, afirma-se que a cinésica estuda os trejeitos faciais, em particular o movimento dos olhos, posturas corporais e a gesticulação. Para os referidos autores (1999, p. 52) "A cinésica, enquanto prática não verbal serve ao controle individual das interações sociais."

Conhecer a linguagem não verbal é ter condições de compreender melhor a si mesmo e aos outros. O comportamento das pessoas transmitem emoções desejadas e indesejadas, conscientes e inconscientes, isto é, o corpo por meio da comunicação não verbal expressa atitudes e sentimentos de forma voluntária e involuntária.

O antropólogo Bridwhistell foi pioneiro a tentar compreender a linguagem do corpo. Para esse estudioso "[...] não há gestos ou movimentos corporais que possam ser considerados como símbolos universais e, que toda cultura tem seu repertório gestual." (BRIDWHISTELL 1985 apud SILVA et al., 2000, p. 53).

O ser humano é capaz de compreender o outro não somente pela fala, mas também por meio das expressões e manifestações corporais. Entretanto, Silva et al. (2000, p. 3) lembram que "[...] os gestos são compreendidos de diversas formas nas diferentes culturas [...]", isto é, os gestos são inúmeros e seus significados podem variar de uma cultura para outra.

Embora Bridwhistell (1985 apud SILVA et al., 2000) afirme que não há símbolos universais, na literatura especializada é possível se deparar com a existência de comportamentos não verbais que podem ser considerados universais, como por exemplo, o sorriso. Entretanto, o sorriso ainda pode apresentar diversos significados, isto é, expressar alegria, felicidade, ironia, entre outros aspectos.

O ser humano é um ser observado o tempo todo e de acordo com Gaiarsa (2002, p. 14) "A expressão não verbal do ser humano é considerada o principal objeto da Psicologia, isto é, tudo aquilo que não é dito pela palavra, pode ser encontrado no tom de voz, na expressão do rosto, na forma do gesto ou na atitude do personagem." 
As pessoas não são apenas vistas, mas de acordo com Adler e Towne (2002) elas são observadas, não pelo que dizem, mas sim pelo que fazem. Diante do contexto, é possível afirmar que compreender as mensagens não verbais é de suma importância para a competência comunicativa.

\subsection{Proxêmia}

A proxêmia estuda o uso que o homem faz do espaço que o rodeia, a distância e proximidade entre ele e outros seres e objetos. Hall (1977, p. 95) destaca que "[...] a expressão proxêmia é empregada para definir as observações e teorias inter-relacionadas sobre o uso que o homem faz do espaço." Rector e Trinta (1999), afirmam que essa disciplina estuda o uso humano do espaço para fins de comunicação, ou seja, é a relação social do homem com o espaço que o cerca.

Considerado precursor da análise do uso que o ser humano faz do espaço que utiliza, bem como daquele que o rodeia, o antropólogo Edward Hall considera a proxêmia um aspecto de extrema relevância no que tange a instituição de vida em sociedade; pois ao observar os acessórios, os objetos, quadros, tapetes, a decoração de uma casa, é possível interpretar quem nesta casa habita. Tal interpretação também pode ser inferida no ambiente de trabalho, na organização de uma mesa, na disposição dos móveis, na iluminação de um ambiente, entre outros.

A tendência do ser humano é personalizar o espaço, isto é, por meio da decoração, da disposição do mobiliário, da construção de barreiras mais ou menos visíveis, ele manifesta sua identidade. Ainda por intermédio dessa personalização as pessoas recebem informações acerca do gosto, das preferências, as opiniões e até mesmo os hábitos do indivíduo (FISCHER, 1993).

A literatura destaca que a relação espacial entre os indivíduos, a distância que eles se colocam entre si, fazem parte do processo de comunicação. Hall (1977 apud FAST, 1999) ressalta que o uso que o homem faz do espaço, apoia-se em sua capacidade de se relacionar com outras pessoas e senti-las como próximas ou distantes.

Segundo Hall (1977) o espaço e a distância que o homem mantém de outros seres não é estático, uma vez que se modifica a cada instante ou situação. Por meio do uso do espaço o homem pode exteriorizar seus sentimentos. Para o autor, o homem defende seu território a partir de quatro zonas de distâncias: a distância íntima, a distância pessoal, a 
distância social e a distância pública. Quanto maior for a distância, menor será o grau de intimidade.

Por meio da distância mantida entre as pessoas é possível interpretar como uma se sente em relação à outra ou tipo de situação que se estabelece. De acordo com Hall (1977) as distâncias podem ser consideradas da seguinte forma:

- A distância íntima é considerada até quarenta e cinco centímetros e é definida como uma distância de um compromisso, chamada de distância familiar. É onde as características do rosto, corpo, temperatura, odor, ficam expostos.

- A distância pessoal é entre cinquenta centímetros e um metro e vinte. É a distância utilizada quando se está no elevador com alguém, numa sala de espera, está distância poderia ser imaginada como uma espécie de esfera ou bolha protetora que as pessoas matem entre si e os demais.

- A distância social está entre um metro e vinte e três metros e cinquenta. É comum em ambientes profissionais, mas é administrada pelas pessoas que interagem dentro desse espaço.

- A distância pública é a distância de mais de três metros e cinquenta, geralmente utilizada com desconhecidos e formalmente. Nessa distância pode-se também perceber o comportamento individual quando se está em multidões, a pessoa pode demonstrar que não tem interesse em manter diálogo com a outra.

Outro aspecto a ser evidenciado diz respeito à territorialidade. Adler e Towne (2002, p. 126) esclarecem que "[...] enquanto o espaço pessoal é a bolha invisível que carregamos como uma extensão do nosso ser físico, o território permanece estacionário." Para Fischer (1993) o espaço pessoal é diferente de território, pois o espaço pode ser definido como uma fronteira invisível em torno das pessoas, enquanto o território é uma área visível, estável e muitas vezes, claramente demarcada.

Pode-se dizer que na territorialidade o ser humano ou animal delimita direitos assumidos em determinado território, isto é, ele toma posse de alguns locais como sendo seu, sentem-se proprietários de determinados lugares. Alguns exemplos típicos podem ser a carteira da escola, seu quarto em casa, seu lugar na mesa no horário das refeições, pessoas que ao frequentarem as igrejas sentam-se sempre no mesmo lugar, entre outros.

No que tange aos aspectos de territorialidade, Lunardelli e Queiroz (2005, p. 3) salientam que: 
Tanto os espaços territoriais quanto os corporais conferem hierarquias e regras, já que sua organização expressa distâncias, lugares e posições que ocupam os indivíduos, e, dentro de cada cultura, os interlocutores conhecem implicitamente quais são as distâncias adequadas para cada tipo de interação ou relação.

Baseado no exposto observa-se que o uso do espaço pelo ser humano é essencial para os estudos das comunicações não verbais.

\subsection{Paralinguagem}

A paralinguagem ou prosódia preocupa-se com a entonação e as mensagens que são transmitidas pela voz, pois algumas características da voz transcendem a fala, isto é, a altura e a intensidade da voz, as pausas, o sussurro, a duração, entre outros aspectos, influenciam a mensagem em que se pretende transmitir.

Segundo Adler e Towne (2002, p. 120) “[...] a própria voz é outro canal de comunicação não-verbal. Os cientistas sociais usam o termo paralinguagem para descrever as mensagens vocais não-verbais." De acordo com os autores a diferente pronúncia de uma mesma palavra pode apresentar vários significados. A comunicação não verbal da voz está presente no tom, no ritmo, na altura, no volume, no sarcasmo, na ironia, entre outros aspectos que a voz pode apresentar.

A prosódia era tradicionalmente o estudo das variações de quantidades, de altura e de intensidade da voz. Entretanto, com a linguística moderna, esses fenômenos prosódicos da fonemática ${ }^{4}$, passaram a estudar os sons segundo suas características articulatórias (GUIRAUD, 2001).

As inflexões de voz, a mímica facial e os gestos das mãos e do corpo são aspectos emocionais da fala conhecidos como prosódia. Além desses aspectos emocionais, a prosódia permite também que o emissor e o receptor diferenciem uma afirmação de uma interrogação e de uma exclamação.

Guiraud (2001, p. 88) afirma que "[...] a fala se desenvolve numa linha dupla [...]", ou seja, por um lado estuda a sequência dos sons articulados, e por outro lado, estuda a variação da voz, cuja principal função é exprimir as emoções do locutor que pode pronunciar uma frase gritando, murmurando, irritado, angustiado, curioso, surpreso, entre outros.

\footnotetext{
${ }^{4}$ Fonemática, de acordo com o Dicionário Houaiss, é a parte da fonologia que se ocupa, especificamente, dos fonemas segmentais e tem por fim estabelecer o inventário destes, classificá-los, estudar-lhes as combinações etc.
} 
Constituindo-se como aspecto relevante da comunicação entre locutor e ouvinte, muitas vezes a entonação é muito mais observada do que a própria palavra, pois a voz poderá manifestar seu estado emocional, expressando a tranquilidade, o nervosismo, o medo, a raiva, etc. Adler e Towne (2002, p. 122) destacam que "A comunicação através da paralinguagem nem sempre é intencional. Muitas vezes a voz nos denuncia quando estamos tentando criar uma impressão diferente de nossos reais sentimentos."

Vale lembrar que as mudanças que ocorrem na voz podem contradizer as palavras pronunciadas, pois em momentos de raiva e nervosismo, a voz poderá soar mais alta sem que o locutor perceba, ou, em um momento de tristeza e dor, sua fala poderá soar reprimida e num tom mais baixo.

Assim como os gestos reforçam ou contradizem a mensagem, as comunicações vocais ou a paralinguagem também têm essa capacidade. A fala humana difere da fala de um robô, visto que tem nuances e entonações de voz que conferem a ela um conteúdo emocional capaz de modificar o sentido racional das frases.

De acordo com o panorama apresentado, percebe-se que na contação de histórias a comunicação verbal e não verbal estão intrinsecamente ligadas, pois além da fala, as expressões faciais, os gestos, a entonação de voz, entre outros, estão presentes em toda e qualquer atividade relacionada.

\subsection{Linguagem Não Verbal e a Contação de Histórias}

Como anteriormente mencionado, na atividade de Contação de Histórias várias questões contribuem para seu sucesso como, por exemplo, a escolha da história, o local onde a história está sendo apresentada, bem como o modo de se contar histórias ou a habilidade do contador em se comunicar.

Com relação ao modo de contar as histórias, vários fatores contribuem para sua realização e pode-se destacar o conhecimento da história, o entusiasmo do contador e a comunicação não verbal que se instaura por intermédio dos gestos corporais do contador, a distância entre o contador e seus ouvintes e a entonação que utiliza nos diversos trechos da história. Em decorrência, observa-se a importância de estudos acerca da comunicação por meio da linguagem não verbal na contação de histórias.

Ainda que não seja empregada a terminologia científica utilizada para conceituar as linguagens não verbais, vários autores e entre eles: Barcellos e Neves (1995); Busatto (2003); Piza (2006); Matos e Sorsy (2007); Brenman (2012); Sisto (2012) apontam a sua 
relevância no que diz respeito ao sucesso dessa atividade no momento em que valorizam os gestos, a entonação de voz, entre outros aspectos no processo comunicacional.

Segundo Matos e Sorsy (2007, p. 7) "As expressões do corpo, os gestos, o ritmo e a entonação da voz imprimem sentido às palavras e desvelam para o ouvinte as emoções por trás do texto."

$\mathrm{Na}$ comunicação facial, o contador poderá informar fortemente o seu estado emocional para quem ouve a história, por este motivo é importante que as expressões faciais sejam coerentes com as emoções a serem transmitidas aos seus ouvintes, pois as emoções manifestam diferentes significados, dentre eles felicidade, alegria, insegurança, medo, raiva, desprezo, etc.

Brenman (2012, p. 105) destaca que "As entonações vocais registram uma infinidade de emoções, que são constantemente alimentadas pelas reações dos ouvintes." Entretanto, o autor complementa que "a voz, por sua vez, não trabalha sozinha, ela reverbera em todo o corpo do contador: os olhos, os gestos, a expressão facial. $O$ narrador oral é um artista da voz e do gesto." (BRENMAN, 2012, p. 105).

De acordo com o panorama apresentado, evidencia-se a estreita ligação entre aspectos da linguagem não verbal e a Contação de Histórias. Nesse sentido, é possível afirmar que o conhecimento da linguagem não verbal adquirido pelo Contador de Histórias poderá ampliar sua percepção a respeito das interações, bem como aumentar a qualidade da atividade da Hora do Conto.

\section{PROCEDIMENTOS METODOLÓGICOS}

Com o intuito de identificar a percepção dos contadores de histórias que realizam a Hora do Conto nas Escolas do Município de Londrina a respeito da importância da linguagem não verbal para a realização de suas atividades, ou seja, quais são as informações que possuem acerca da linguagem não verbal, o percurso metodológico foi seguido a partir de uma pesquisa descritiva e exploratória, com abordagem qualitativa.

Os participantes da pesquisa foram Professores Regentes de Oficinas de Bibliotecas (PROB) doravante denominados contadores de história, conhecidos também como professor da Hora do Conto das Escolas Municipais de séries iniciais de Londrina, que participam do Projeto Bibliotecas Escolares: Palavras Andantes. 


\subsection{Projeto Bibliotecas Escolares: Palavras Andantes}

O Projeto Bibliotecas Escolares: Palavras Andantes é um projeto de leitura que foi estruturado para a Rede Municipal de Ensino de Londrina, visando promover a formação continuada dos professores da hora do conto, bem como a revitalização dos espaços destinados à biblioteca. Tal projeto teve seu início em abril de 2002 e seu precursor foi Rovilson José da Silva, que atuou durante muitos anos como professor em escolas de ensino fundamental.

Atualmente o projeto, implantado em 2002, continua em pleno funcionamento. E os professores que participam de tal projeto constituiu o público alvo desta pesquisa.

Importa mencionar que o projeto em questão, no ano de 2008 participou da premiação do Vivaleitura, iniciativa do Ministério da Educação que incentiva a formação de leitores em todo o país e conquistou o título de melhor projeto de leitura do país (PALAVRAS..., 2008).

\section{ANÁLISE E DISCUSSÃO DOS RESULTADOS}

Como anteriormente mencionado, os participantes da pesquisa são professores da Rede Municipal de Londrina, conhecidos como Professores Regentes de Oficina de Bibliotecas (PROB) que realizam a Hora do Conto nas Escolas Municipais de séries iniciais em Londrina.

A aplicação do questionário aconteceu no mês de outubro do ano de2012, no período matutino. Estavam presentes na reunião mensal 48 pessoas, sendo entregue um questionário para cada um. Destes, 45 foram respondidos, 2 devolvidos em branco e 1 questionário não foi devolvido.

Para alcançar os objetivos propostos verificou-se a formação profissional dos contadores de histórias, seu tempo de atuação no projeto Palavras Andantes, entre outros.

Diante do contexto, foi possível constatar que a formação dos PROB são nas mais diversas áreas do conhecimento, isto é, possuem formação heterogênea, sendo 65 \% dos participantes possuem formação em Pedagogia, enquanto os $35 \%$ restantes ficam divididos nas áreas de Letras, História, Geografia, Ciências Sociais, Normal Superior, Educação Artística e Artes Plásticas, o que para Silva $(2010$, p. 76) "[...] é comum no 
ensino fundamental nas séries iniciais. Nesse período de ensino, o professor regente de sala de aula leciona, praticamente, todas as disciplinas para a turma."

No que se refere ao tempo de atuação no projeto, é possível detectar certa rotatividade dos $\mathrm{PROB}$ nas bibliotecas de suas escolas, fator que possivelmente reforça a ideia de que realizar os trabalhos como professor regente de biblioteca não é sinônimo de realizar um trabalho fácil, nem que exige pouco preparo do professor ou que qualquer profissional está habilitado para realizá-la a contento.

Com o intuito de identificar se a linguagem não verbal está presente em suas ações de forma consciente ou inconsciente, a questão 4 solicitou aos participantes que descrevessem as etapas que realizam quando preparam a atividade de contar histórias, dentre elas: leitura prévia da história; escolha da história; utiliza recursos audiovisuais, objetos, musicas, roupas, etc; preparação do ambiente; acomodação dos alunos para ouvirem a história; possibilita comentários a respeito da história; apresenta o autor/ilustrador; reflete a respeito da caracterização dos personagens, voz; finaliza com feedback; busca as crianças na sala de aula; utiliza cartaz, painéis, enfeites; impressões acerca da capa; impressões acerca da capa; observa o envolvimento da criança - brilho nos olhos; cronometra o tempo que precisará para contar a história.

A etapa que mais se destacou foi a leitura prévia da história, momento muito importante para o contador de histórias que deseja realizar a hora do conto com sucesso, sem surpresas indesejáveis. Isto é, conhecer a história, os personagens, dominar o assunto é muito importante ainda mais quando irá trabalhar com pequenos curiosos.

De acordo com os resultados obtidos foi possível destacar que os professores julgam necessário escolher a história, utilizar recursos audiovisuais, objetos, músicas, roupas, preparar o ambiente, acomodar os alunos para ouvirem a história, possibilitar comentários da história, apresentar o autor/ilustrador, refletir a respeito da caracterização e voz dos personagens, observar o envolvimento da criança, entre outros fatores.

Analisando as respostas, observou-se que, de forma consciente ou inconscientemente a linguagem não verbal está presente na preparação da atividade de contação de histórias do $\mathrm{PROB}$, pois eles mencionaram a etapa de preparação do ambiente, de acomodação dos alunos para ouvirem a história, reflexão a respeito da caracterização e voz dos personagens. O cotejamento das respostas com a literatura especializada indica a confluência de pensamentos entre os professores e especialistas da área, pois como apresenta Barcellos e Neves (1995, p. 26-27): 
- O narrador deve ter o cuidado de preparar o ambiente da realização da Hora do Conto;

- quando a Hora do Conto é realizada na biblioteca, sugere-se a preparação de um espaço que poderá ser denominado Cantinho da História;

- na sala de aula, deverá ser mudada a disposição das classes. Ao invés de uma atrás da outra, estas poderão formar um círculo [...];

- em espaços abertos, deve ser dada preferência ao abrigo oferecido pelas árvores, quando as condições climáticas assim o permitem.

É importante mencionar que no emprego, por parte dos respondentes, das expressões "preparação de um espaço" e "disposição das classes", observa-se nitidamente o repertório linguístico das ações que estão relacionadas a proxêmia.

$\mathrm{Na}$ sequência, por meio de uma questão aberta, detectou-se também que os recursos são mais utilizados são os livros; fantoches; dvd's, filme, vídeo e tv; cd's, músicas, rádio, toca cd; roupas, roupas típicas, figurino, fantasia, caracterização; data show; voz, entonação de voz; revistas, gibis; corpo, expressão corporal, gestos; retroprojetor; adereços, bexigas, máscaras; cartazes, painéis; computador; objetos; varal de contação, avental; fotos, gravuras; artes, pinturas, sucata; bonecos; dramatização, teatro; internet; pendrives; dedoches; linguagem interativa; materiais pedagógicos; cartas de leitura; tapetes; instrumentos musicais.

Diante das respostas obtidas, constatou-se que boa parte (33 participantes) utilizase dos livros para contação de histórias; entretanto, é possível perceber que alguns vão além deles, uma vez que utilizam fantoches, roupas típicas, fantasias, varal de contação, avental, retroprojetor, gestos, entonação de voz, expressão corporal, entre outros.

Diversos são os recursos que podem ser utilizados no momento da atividade. Dos PROBS pesquisados $50 \%$ fazem uso de fantoches no momento da contação de histórias. Segundo Barcellos e Neves (1995, p. 66) "[...] para todas as disciplinas o teatro de fantoches contribui para alcançar objetivos de ensino. No entanto, é no desenvolvimento da linguagem escrita e/ou falada que encontra maior aplicação."

O retroprojetor também mencionado pelos participantes pode ser utilizado em diversas situações, isto é, à medida que o contador vai contando a história, pode ir projetando na tela as imagens da história, bem como, o contador pode projetar as imagens e solicitar que as crianças narrem a história (BARCELLOS; NEVES, 1995).

De acordo com as informações obtidas, constatou-se mais uma vez que os PROB desenvolvem as atividades de acordo com as premissas apresentadas pela literatura específica. 
Dando continuidade à análise, investigou-se o grau de importância dada aos seguintes aspectos relacionados a contação de histórias: conhecimento da história; fatores climáticos (frio/calor); mudança de entonação em vários momentos; uso de objetos; detalhes da vestimenta; gestos; distância entre o contador e os alunos; posição corporal do contador; aumento e/ou diminuição da velocidade da fala (falar rápido ou lentamente).

As respostas evidenciaram que o conhecimento da história, a mudança de entonação em vários momentos, os gestos, a distância entre o contador e os alunos, a posição corporal do contador e o aumento e/ou diminuição da velocidade da fala (falar rápido ou lentamente) são aspectos considerados muito importantes no momento da contação de histórias.

Importa mencionar que a mudança de entonação em vários momentos e 0 aumento e/ou diminuição da velocidade da fala (falar rápido ou lentamente) são aspectos relacionados a paralinguagem, assim como, os gestos, a posição corporal do contador são aspectos relacionado a cinésica, bem como a distância entre o contador e os alunos é um aspecto relacionado a proxêmica.

Foi possível perceber também que 17 participantes apontaram que os fatores climáticos (frio/calor), aspectos relacionados as questões corporais não são importantes no momento da contação de histórias.

Entretanto, vale ressaltar que na preparação do ambiente ou local o qual se dará a referida atividade é importante que não seja um local exposto ao sol, numa sala demasiadamente quente ou fria na qual o calor ou o vento podem tirar o conforto e a atenção das crianças.

Dando continuidade ao estudo, buscou-se identificar se os participantes conheciam os termos a seguir:

Tabela 1 - Conhecimento acerca dos termos cinésica, proxêmica e paralinguagem

\begin{tabular}{l|c|c|c|c}
\hline & SIM & NÃO & VAGAMENTE & BRANCO \\
\hline CINÉSICA & 10 & 19 & 12 & 4 \\
\hline PROXÊMICA & 2 & 28 & 12 & 3 \\
\hline PARALINGUAGEM & 14 & 14 & 13 & 4 \\
\hline
\end{tabular}

Fonte: Dados da pesquisa

Analisando a tabela é perceptível que os PROB não têm conhecimento ou conhecem vagamente os termos relacionados à linguagem não verbal que se fazem tão 
presentes em suas atividades na hora de contar histórias. Entretanto, é importante ressaltar que o fato de não conhecer os termos científicos empregados para definir esses aspectos não verbais não significa que os contadores de histórias não se utilizem dessa modalidade comunicacional.

No que tange a distância mantida entre o contador e as crianças no momento da hora do conto, obteve-se o seguinte resultado:
Distância íntima - 06 participantes;
Distância pessoal - 32 participantes;
Distância social - 9 participantes;
Distância pública - 2 participantes.

É importante destacar que dois participantes não assinalaram nenhuma opção, entretanto, outros dois participantes mencionaram fazer uso de todas as distâncias, justificando que as mesas ficam longe e que nas rodas alguns ficam mais longe e outros mais próximos. Ainda outros dois participantes deixaram de assinalar as opções.

No que se refere à distância mantida entre os contadores de histórias e seus ouvintes, embora os PROB tenham respondido que não conheciam o termo proxêmica, ela se faz presente no momento da contação de histórias, pois a maioria dos contadores responderem que mantem a distância pessoal dos seus ouvintes. Conforme mencionado anteriormente Hall (1977) descreve as distâncias da seguinte forma: distância íntima inferior a $45 \mathrm{~cm}$; distância pessoal - entre $50 \mathrm{~cm}$ a $1,20 \mathrm{~m}$; distância social - entre 1,20 a 3,50m e distância pública - acima de 3,50m.

Em análise a resposta observou-se que seis participantes assinalaram a opção distância íntima. Nesse sentido acredita-se que tal opção pode ter sido assinalada por engano, pois para se contar histórias a essa distância, provavelmente o PROB teria que acomodar a criança em seu colo, uma vez que trata-se de uma distância muito próxima. $\mathrm{Na}$ concepção de Hall a distância intima é considerada uma distância de pele, do contato intimo e muitas vezes amoroso.

Vale destacar ainda que dois participantes assinalaram a opção distância pública. Tal opção deduz-se, também pode ter sido equivocada, pois presume-se que contar histórias a essa distância seria inviável, a menos que contador estabeleça essa distância em função de contar histórias em um auditório para um público consideravelmente grande e para tanto utilize microfone. 
Na sequência procurou-se conhecer qual é a disposição espacial das crianças na hora da contação de histórias, pois considerando que a proxêmica significa o emprego que o homem faz do espaço que o envolve, e que é no espaço ocupado pelas crianças que acontece a sociabilidade. As opções foram: semicírculo; encostadas nas paredes; cada criança sente onde quer; outras.

Em análise as respostas, percebeu-se que alguns respondentes informaram que as crianças ficam em semicírculo na hora da contação de histórias, isto é, as crianças sentam-se voltadas para o contador. Outros comunicaram que as crianças sentam onde quer e apenas um dos participantes respondeu que suas crianças ficam encostadas nas paredes. Acredita-se que não é uma disposição espacial adequada, pois dificulta o envolvimento social e afetivo das crianças num momento que é para ser lúdico e extremamente afetivo.

Percebeu-se também que a opção "outras" também se destacou. Em decorrência, a seguir serão apresentadas as justificativas dadas pelos 26 participantes que assinalaram esse item. É importante esclarer que a opção "outras" solicitava que o respondente explicasse o porque de assinalar esta opção, diante disso, vale mencionar também que 22 justitificaram apenas uma ação, enquanto outros 4 mencionaram mais de uma ação. Ao assinalar tal opção os respondentes justificaram que a disposição espacial das crianças: variam de disposição de acordo com a história; sentam em cadeiras/mesas; em tapetes/colchonetes; no patio da escola.

Ainda que as crianças também tenham a liberdade de se sentar onde querem conforme resposta de alguns respondentes, é possível perceber na opção "outras", que elas ainda estão limitadas a se sentarem em cadeiras com mesas. Tal fato pode ser justificado pela falta de espaço, conforme os contadores de histórias mencionam em vários momentos do questionário nas questões abertas.

Outra "leitura" da situação levanta a hipótese de que tal atividade ainda pode estar sendo realizada apenas como um momento de ensinar a leitura e a escrita, (atividade de cunho acadêmico, apenas) e, portanto, pode ser considerado natural que as crianças permaneçam sentadas em cadeiras.

No que diz respeito as atividades que são realizadas após a finalização das histórias, identificou-se que as mais realizadas são a discussão, comentários a respeito do que mais gostaram da história, atividades relacionadas a artes, empréstimo de livros, atividades variadas (interpretação oral, recitação de poesia, exposição das impressões 
sobre a história, as crianças manuseiam os livros). Dois respondentes destacaram que não realizam nenhuma atividade, pois o tempo é curto e as turmas são numerosas. Identificou-se também que alguns participantes ainda relacionam a hora do conto com pinturas, confecção em dobradura, entre outras atividades. De acordo com Silva (2010, p. 61) "[...] é como se o livro e a leitura não bastassem por si próprios."

Acredita-se que uma das finalidades da hora do conto seja a de proporcionar um momento lúdico para as crianças, sem o compromisso de determinar conteúdos a serem estudados. Sisto (2012, p. 25) destaca que "Quando a história contada vem em função de instaurar um espaço lúdico, ela pode gerar um outro tipo de expectativa: não mais a da cobrança, mas a do encantamento."

Solicitou-se ainda que o contador de histórias descrevesse como as crianças ocupam o espaço após a finalização da história.

Conforme mencionado, o ouvinte poderá usar o espaço ou a distância para externar seus sentimentos em relação à outra pessoa, em relação ao momento, ao contexto da conversa e aos objetivos interpessoais (HALL 1977 apud ADLER; TOWNE, 2002).

Em análise as respostas, pode-se inferir que as crianças após a finalização da história, chegam mais perto dos colegas, bem como do contador de histórias. Essa aproximação pode significar o estabelecimento de relações mais estreitas, mais afetiva entre eles, fator que pode ser interpretado como ponto positivo na realização da atividade.

Em contrapartida, se as crianças permanecem no mesmo lugar ou vão para as mesas trabalhar em grupos, fica a dúvida se a contação não está sendo realizada apenas por motivos como, por exemplo, apresentar mensagens de cunho moral, passar o tempo enquanto a professora descansa ou outro motivo similar. Neste caso, a contação poderá ser vista como atividade de aquisição de constructos cognitivos ou morais apenas.

\section{CONSIDERAÇÕES FINAIS}

Ler é um ato muito importante para o desenvolvimento cultural e social de qualquer cidadão. Neste contexto, a biblioteca escolar ganhou destaque por exercer papel fundamental para a sociedade, pois é nela que muitas crianças têm seu primeiro encontro com o livro e a literatura. De acordo com o panorama de valorização do gosto e hábito da 
leitura, o estudo em tela buscou destacar o valor da biblioteca escolar, da contação de histórias, bem como o papel da linguagem não verbal na atividade da hora do conto.

Considerando que a linguagem verbal e não verbal estão intrinsecamente imbricadas na contação de histórias, o presente estudo verificou a percepção dos contadores de histórias da Rede Municipal de Londrina a respeito dessa relação. A escolha deste público alvo não foi um mero acaso, a razão é que estes professores participam de um projeto que conquistou o título de melhor projeto de leitura do país.

Por intermédio das respostas obtidas constatou-se que muitos dos respondentes preocupam-se com a entonação, com as expressões corporais no momento da contação de histórias ainda que desconheçam a terminologia empregada para identificar esses aspectos.

Entretanto, no que tange ao uso do espaço como fator de comunicabilidade ou interação, acredita-se que a maioria deles não tem conhecimento a respeito. Em outros termos, observou-se que os PROB, muitas vezes, estabelecem a configuração do espaço a ser ocupado pelas crianças sem se preocupar com os efeitos (positivos ou negativos) que tal decisão poderá acarretar.

As informações de que as crianças permanecem sentadas em cadeiras e mesas para ouvirem as histórias, leva a crer que no momento da contação de histórias, a atividade pode deixar de ter o aspecto de lúdico, de fruição e de aprendizagem de forma positiva para transformar-se em mais uma atividade meramente pedagógica, de caráter informativo e formativo impingido às crianças.

Em decorrência, espera-se que os resultados deste estudo sirvam de estímulo à continuidade e aprofundamento das reflexões a respeito das linguagens não verbais na contação de histórias bem como na criação de novos conhecimentos a respeito.

\section{REFERÊNCIAS}

ABRAMOVICH, Fanny. Literatura infantil: gostosuras e bobices. 5. ed. São Paulo: Scipione, 1997.

ADLER, Ronald B; TOWNE, Neil. Comunicação interpessoal. Rio de Janeiro: LTC, 2002.

BAMBERGER, Richard. Como incentivar o hábito de leitura. 6. ed. São Paulo: Ática, 1995. 
BARCELLOS, Gládis Maria Ferrão; NEVES, lara Conceição Bitencourt Neves. A hora do conto: da fantasia ao prazer de ler. Porto Alegre: Sagra, 1995.

BORGES, Silvia Bortolin; BORTOLIN, Sueli. Hora da história: toda criança merece. In: BARROS, Maria Helena T. C.; BORTOLIN, Sueli; SILVA, Rovilson José. Leitura: mediação e mediador. São Paulo: FA., 2006. p. 139-146.

BRASIL. secretaria de Educação Fundamental. Parâmetros Curriculares Nacionais: língua portuguesa. 1997a. Disponível em: <http://portal.mec.gov.br/seb/arquivos/pdf/livro02.pdf>. Acesso em: 17 jul. 2012.

Parâmetros Curriculares Nacionais 1a a 4⿳亠 Séries. Brasília: MEC/SEF, 1997b. Disponível em: <http://portal.mec.gov.br/seb/arquivos/pdf/livro01.pdf>. Acesso em: 17 jul. 2012

BRENMAN, Ilan. Através da vidraça da escola: formando novos leitores. 2. ed. Belo Horizonte: Aletria, 2012.

BUSATTO, Cléo. A arte de contar histórias no século XXI. Petrópolis: Vozes, 2006. Contar e encantar: pequenos segredos da narrativa. Petrópolis: Vozes, 2003.

CALDEIRA, Paulo da Terra. O espaço físico da biblioteca. In: CAMPELLO, Bernadete dos Santos et al. A biblioteca escolar: temas para uma prática pedagógica. Belo Horizonte: Autêntica, 2005. p. 47-49

CALDIN, Clarice Fortkamp. A oralidade e a escritura na literatura infantil: referencial teórico para a hora do conto. Enc. Bibli: R. Eletr. Bibliotecon. Ci. Inf., Florianópolis, n. 13, maio, 2002. Disponível em: <https://periodicos.ufsc.br/index.php/eb/article/view/15182924.2002v7n13p25/5213>. Acesso em: 27 jul. 2012.

CAMPELLO, Bernadete dos Santos. Biblioteca e parâmetros curriculares nacionais. In: CAMPELLO, Bernadete dos Santos et al. A biblioteca escolar: temas para uma prática pedagógica. Belo Horizonte: Autêntica, 2005. p. 17-19.

CASTRO FILHO, Cláudio Marcondes de; COPPOLA JUNIOR, Claudinei. Biblioteca escolar e a lei 12.244/2010: caminhos para implantação. Bibl. Esc. em R., Ribeirão Preto, v. 1, n. 1, p. 30-41, 2012. Disponível em:

<http://revistas.ffclrp.usp.br/BEREV/article/view/102/82>. Acesso em: 9 jul. 2012.

COELHO, Betty. Contar histórias: uma arte sem idade. 8. ed. São Paulo: Ática, 1998.

COELHO, Nelly Novaes. Literatura infantil: teoria, análise e didática. 7. ed. São Paulo: Moderna, 2000.

FAST, Julius. A linguagem do corpo. São Paulo: Livraria Nobel, 1999. 
FERRAZ, Clarice Vanderlei. A inclusão da biblioteca escolar no projeto político pedagógico da escola. In: CONGRESSO BRASILEIRO DE LEITURA (COLE), 17., 2009. Campinas. Anais eletrônicos... Campinas: Faepex, 2009. Disponível em: $<$ http://alb.com.br/arquivomorto/edicoes_anteriores/anais17/txtcompletos/sem01/COLE_267.pdf>. Acesso em: 09 jul. 2012.

FISCHER, Gustave-Nicolas. Espaço, identidade e organização. In: CHANLAT, JeanFranços (Coord.). $O$ indivíduo na organização: dimensões esquecidas. São Paulo, Atlas, 1993, v. 2, p. 81-102.

FONEMÁTICA. In: HOUAISS, Antonio. Dicionário eletrônico Houaiss da língua portuguesa. Rio de Janeiro: Editora Objetiva, 2001. (CD-ROM).

GAIARSA, José Ângelo. O corpo fala? Motriz, Rio Claro, v. 8, n. 3, p. 85-90, set/dez. 2002. Disponível em: <http://www.rc.unesp.br/ib/efisica/motriz/08n3/Gaiarsa.pdf>. Acesso em: 29 jun. 2012.

GUIRAUD, Pierre. A linguagem do corpo. São Paulo: Ática, 2001.

HALL, Edward T. A dimensão oculta. Rio de Janeiro: Francisco Alves, 1977.

LEMOS, Ilsa Solka. A comunicação não verbal: um estudo de caso. UNIrevista, Porto Alegre, v. 1, n. 3, jul. 2006. Disponível em:

<http://www.unirevista.unisinos.br/_pdf/UNIrev_Lemos.PDF>. Acesso em: 17 maio 2013.

LUNARDELLI, Rosane S. A.; QUEIROZ, Solange Palhano de. A proxemia e o fazer bibliotecário. Inf. \& Inf., Londrina, v. 10, n. 1/2, jan./dez., 2005. Disponível em: <http://www.uel.br/revistas/uel/index.php/informacao/article/view/1737/1486>. Acesso em: 10 jan. 2012.

MATOS, Gislayne Avelar; SORSY, Inno. O ofício do contador de histórias. São Paulo: Martins Fontes, 2007.

PALAVRAS andantes é o melhor projeto de leitura do país. Parana-Online, 14 nov. 2008. Disponível em: <http://www.parana-online.com.br/editoria/policia/news/335503/>. Acesso em: 1 maio 2013.

PIZA, Carmelina de Toledo. Entrou por uma porta saiu por outra, quem quiser que conte outra. Americana: Adonis, 2006.

RECTOR, Mônica; TRINTA, Aluizio Ramos. Comunicação do corpo. 4. ed. Rio de Janeiro: Ática, 1999.

SANTAELLA, Lúcia. Comunicação e pesquisa: projetos para mestrado e doutorado. São Paulo: Hacker, 2002.

SILVA, Lúcia Marta Giunta da et al. Comunicação não-verbal: reflexões acerca da linguagem corporal. Rev.Latino-Am.Enfermagem, Ribeirão Preto, v. 8, n. 4, p. 52-58, ago. 2000. Disponível em: <http://www.scielo.br/pdf/rlae/v8n4/12384>. Acesso em: 10 jun. 2014. 
SILVA, Rovilson José da. Biblioteca escolar e a formação de leitores: o papel do mediador da leitura. Londrina: Eduel, 2010.

SILVA, Rovilson José da; BORTOLIN, Sueli. Reflexões sobre a leitura e a biblioteca escolar. In: SILVA, Rovilson José da; BORTOLIN, Sueli (Org.). Fazeres cotidianos na biblioteca escolar. São Paulo: Polis, 2006. p. 11-19.

SILVA, Waldeck Carneiro da. Miséria da biblioteca escolar. 3. ed. São Paulo: Cortez, 2003.

SISTO, Celso. Textos e pretextos sobre a arte de contar histórias. Belo Horizonte: Aletria, 2012.

\section{Title}

Non-verbal language and storytelling from the perspective of the project "palavras andantes"

\section{Abstract}

Introduction: This paper shows some of the results presented in a monograph of the Specialization Course in School Libraries Management of the State University of Londrina.

Objective: To investigate what is the perception of the professionals who perform the Storytelling in schools in Londrina, about the importance of non-verbal language to carry out this activity.

Methodology: The qualitative approach methodology was used and implemented by means of exploratory and descriptive research in which a questionnaire was administered to the subjects mentioned.

Results: It was observed, among other things, that most storytellers make use, intuitively, of some aspects of non-verbal language in their actions. The importance about the proximity and spatial configurations in Story Time, however, are not yet sufficiently valued by professionals.

Conclusions: Through the research carried out, it is understood that, when acquiring a deeper knowledge of the subject, the quality of the Story Time will improve significantly. In this sense, it is hoped, with this study, to contribute to the reflection of storytellers on the importance of non-verbal language in storytelling.

Keywords: Storytelling. School library. Non-verbal language. Paralanguage. Kinesics. Proxemics.

\section{Título}

El languaje no verbal y la narración em la perspectiva del proyecto "palavras andantes"

\section{Resumen}

Introducción: Este artículo trae algunos de los resultados que se presentan en una monografía de Especialización en Gestión de Bibliotecas Escolares de la Universidad Estadual de Londrina 
Objetivo: Investigar cuál es la percepción de los profesionales que desarrollan la hora del cuento en las escuelas del municipio de Londrina, acerca de la importancia del lenguaje no verbal para llevar a cabo esa actividad.

Metodología: La metodología con enfoque cualitativo, realizado por um estudio exploratorio y descriptivo en la que se administró um cuestionario a los sujetos mencionados.

Resultados: Se observó, entre otros aspectos, que la mayoría de los narradores se valen, de forma intuitiva, algunos aspectos del lenguaje no vebal en sus acciones. La importancia de la proximidad y configuraciones espaciales en La Hora del Cuento, sin embargo, no son lo suficientemente valorado por los profesionales.

Conclusiones: A través del cuestionario, se entiende que, al adquirir um conocimiento más profundo del tema, la calidad de la hora del cuento mejorará significativamente. En este aspecto, se espera, con los estudios en pauta, contribuir para la reflexión de narradores a la impotancia del lenguaje no vebal en la narración de cuentos.

Palabras clave: Narración de cuentos. Bibliotecas escolares. Lenguaje no verbal. Paralenguaje. Kinésica. proxémica.

Recebido em: 12.11.2014

Aceito em: 22.12.2014 